\section{Gramatização do português brasileiro nos séculos XIX e XX e início do século XXI}

Isabel Cristina Michelan DE AZEVEDO (UESC) icmazevedo2@gmail.com

\section{Gramatization of Brazilian Portuguese in 19th and 20th centuries and the beginning of the 21st century}

\author{
Nahendi Almeida MOTA (UESC) \\ nahendi@hotmail.com \\ Ingrid Bomfim CERQUEIRA (UESC) \\ cerqueira_ingrid@hotmail.com
}

\title{
00000000000
}

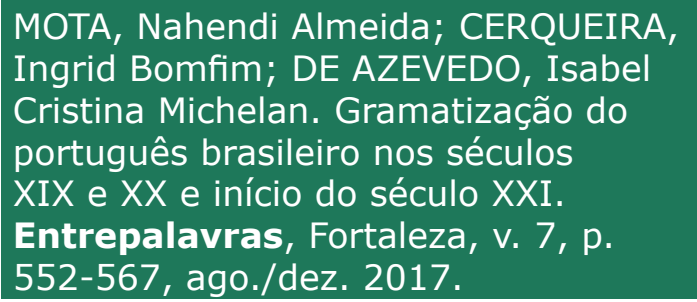

Resumo: Este trabalho tem por objetivo traçar um panorama geral no que diz respeito aos estudos sobre a gramatização do Português brasileiro. Partimos do pressuposto de que, ao longo dos séculos, a legitimação do saber gramatical colocou em xeque a unidade linguística, não sendo mais admissível defender a presença de uma única língua em territórios distintos. Para tanto, recorremos aos pressupostos de Orlandi (2002), para tratar do discurso gramatical em sua relação histórica com o sujeito e suas posições; de Auroux (1992), para conceber a gramatização tal como um processo em que gramáticas e dicionários são tecnologias, para só posteriormente colocarmos a ênfase sobre as Gramáticas Brasileiras Contemporâneas do Português. Focalizamos, assim, como corpus de análise, a Nova gramática do português brasileiro, de Castilho (2010), e a Gramática pedagógica do português brasileiro, de Bagno (2012), para verificar, através de suas introduções e de seus sumários, as posturas assumidas pelos linguistas diante do papel exercido pelos manuais em questão na atualidade e de que maneira o discurso gramatical desses manuais projeta os rumos dos posteriores a eles no século XXI. Além disso, interessa-nos medir até que ponto 
há uma ruptura com a tradição gramatical para que a primeira gramática se declare como "nova", e a última antecipe em seu título certo compromisso com a prática pedagógica, isto é, com o ensino.

Palavras-chave: Gramatização do Português brasileiro. Gramáticas Brasileiras Contemporâneas do Português. Rupturas paradigmáticas.

\begin{abstract}
This study aims at providing a general overview in what concerns the studies on grammatization of the Brazilian Portuguese. We assume that the legitimization of the grammatical knowledge over the centuries have backed linguistic unit into a corner and must not be acceptable to defend the presence of a single language in different territories. For this purpose, we rely on Orlandi's assumptions (2002) to deal with the grammatical discourse in its historical relationship with the subject and its positions; in Auroux (1992) to conceive the grammatization such as a process in which grammars and dictionaries are technologies and then, later, to place emphasis on the Contemporary Brazilian Grammars of the Portuguese. Thus, as analytical corpus, we focus the New Grammar of the Brazilian Portuguese, by Castilho (2010), and the Pedagogical Grammar of the Brazilian Portuguese, by Bagno (2012) in order to verify, through its introductions and summaries, the stances assumed by the linguists before the role played by manuals at stake nowadays and how the grammatical discourse of these manuals project the paths of its successors in 21st century. Moreover, it is of our interest to measure the extent to which there is a split with the grammatical tradition so the first Grammar is declared as "new" and the last one anticipates in its title some commitment to the pedagogical practice, i.e., to the education.
\end{abstract}

Keywords: Grammatization of the Brazilian Portuguese. Contemporary Brazilian Grammars of the Portuguese. Paradigmatic split.

\title{
Introdução
}

Neste artigo tratamos da gramatização - definida por Auroux (1992, p. 65, grifos do autor) como "o processo que conduz a descrever e a instrumentar uma língua na base de duas tecnologias, que são ainda hoje os pilares do nosso saber metalingüístico: a gramática e o dicionário" - do Português Brasileiro (doravante PB), nos séculos XIX e XX e um debate introdutório em torno das prospecções da gramatização do PB no início século XXI, com ênfase nas discussões encontradas nas gramáticas de Ataliba Castilho (2010) e Marcos Bagno (2012).

Para tanto, em um primeiro momento, abordamos a gramatização do Português Brasileiro no século XIX, mostrando qual a função da gramática nesse período, no qual o Brasil estava se individualizando enquanto país e, por conseguinte, uma identidade nacional estava se consolidando, inclusive, por meio da língua.

Em um segundo momento, discorremos acerca da gramatização do $\mathrm{PB}$ no século XX, momento em que, após o fortalecimento da identidade nacional e linguística, a gramática assume uma nova função: a de reforçar divergências e, diferentemente do século anterior, defender 
v. 7 (2)

$552-567$ ago/dez 2017

uma normatividade (baseada no Português Europeu), de forma que as noções de certo e de errado são impulsionadas.

Em um terceiro momento, iniciamos a nossa discussão em torno da função da gramática no século XXI, a qual apresenta gramáticas alicerçadas em teorias linguísticas e centradas no uso, trazendo uma nova postura acerca das noções de erro, norma, normatividade e, portanto, língua.

Como aporte para essas questões, usamos a Nova gramática do português brasileiro, de Castilho (2010), e a Gramática pedagógica do português brasileiro, de Bagno (2012), reconhecidas como exemplos de Gramáticas Brasileiras Contemporâneas do Português (doravante GBCP) no início do século XXI. Logo, analisamos suas introduções e seus sumários - e, caso necessário, trazemos alguns capítulos como exemplos da temática abordada -, com o propósito de verificar quais posturas são assumidas pelos linguistas, diante do papel exercido pela gramática atualmente.

Por fim, de forma introdutória, expomos os rumos que a gramática tem tomado nesses primeiros anos do século XXI e quais são as previsões para os anos posteriores, inclusive, no que tange ao Português no Brasil.

\section{Gramatização do Português Brasileiro no século XIX}

A gramatização do Português Brasileiro durante o século XIX está diretamente relacionada à formação da identidade nacional - a elaboração de gramáticas, dicionários, enciclopédias, etc., mais do que oficializar a nossa língua, contribuíram para a separação entre Brasil e Portugal. Como afirma Orlandi (2002, p. 159), a gramatização da nossa língua está associada à "constituição de um sujeito nacional, um cidadão brasileiro com sua língua própria, visível na gramática", por meio da qual "processos de individualização [...] são desencadeados: individualiza-se o país, seu saber, seu sujeito político e social".

O sujeito nacional ao qual Orlandi (2002) se refere passa a ter sua língua instrumentalizada, legitimada por gramáticas e dicionários, de modo que a unidade visada entre Brasil e Portugal, inclusive no que tange à língua e aos seus aspectos sintático-semânticos, lexicais e fonéticos, é questionada por curiosos acerca da língua. Estes curiosos, posteriormente, tornaram-se gramáticos.

Dessa forma, ainda segundo Orlandi (2002, p. 128), a língua 
falada no Brasil "não é só uma acomodação pragmática do português de Portugal, mas sua historicização divergente", afinal ambas as línguas se desenvolveram em ambientes diferentes, por meio de falantes diferentes - assim, ainda conforme a autora, "se a colonização impõe uma língua, a historicização da língua faz com que essa mesma colonização sofra um deslocamento visível no processo de gramatização".

Reconhecer o PB enquanto a língua de uma nação diferente de Portugal é admitir que a formação da nossa identidade foi consolidada, também, através da gramatização de sua língua - desse modo, é no século XIX que especialistas em disciplinas relativas à linguagem começam a se organizar, juntamente à sistematização de gramáticas nas instituições escolares.

Os responsáveis por essas gramáticas do século XIX não eram, de início, estudiosos da linguagem, mas, sim, historiadores, médicos, engenheiros etc., a exemplo de Júlio Ribeiro e João Ribeiro. O primeiro ficou conhecido como "aquele que significa um discurso fundador da história da gramática brasileira [...] [e que define] a gramática como exposição metódica dos fatos da linguagem'" (ORLANDI, 2002, p. 131). Já João Ribeiro "imprime nova orientação metodológica e realiza uma nova síntese de nosso passado" (ORLANDI, 2002, p. 139), contribuindo para a produção da história do povo brasileiro.

Ainda segundo Orlandi (2002, p. 157), "ao deslocar para o território brasileiro a autoria da gramática, [...] o que os gramáticos brasileiros estão deslocando é a autoridade de se dizer como é essa língua". À vista disso, os gramáticos brasileiros, ao instrumentalizar a língua falada no Brasil, deram autonomia para os brasileiros defini-la como nossa e, portanto, para poder falar sobre ela e através dela. Ser autor de gramática no Brasil foi, portanto, uma maneira de colaborar com o rompimento da tentativa de homogeneização do Português, visto que se passaram a usar escritores brasileiros como exemplo das "belas artes" e do "bom uso" da nossa língua, diferentemente de gramáticos do Português europeu, além de assegurar que as características do PB não são uma maneira "errada" de falar - mesmo que tal posicionamento ainda sustente o senso comum até hoje.

A posição-sujeito ${ }^{1}$ autor de gramática foi, desse modo, muito incisiva no que tange à construção da identidade linguística e entende como a "interpelação do indivíduo em sujeito de seu discurso, a qual se efetua pela identificação (do sujeito) com a formação discursiva que o domina (isto é, na formação que este é constituído como sujeito)" (PECHÊUX, 1997, p. 163). 
v. $7(2)$

$552-567$ ago/dez 2017

nacional dos brasileiros, contribuindo para a apropriação da língua. $\mathrm{E}$, com o surgimento da Linguística, enquanto disciplina científica, o conhecimento metalinguístico colabora, através da constituição de lugares de representação do sujeito brasileiro e da Língua Portuguesa, com o conhecimento em torno da língua nacional.

Por fim, durante o século XIX, a gramatização da Língua Portuguesa está atrelada à tentativa de consolidação do Estado e, por conseguinte, do cidadão brasileiro e de sua identidade linguística e nacional - assumindo, com clareza, suas divergências em relação a Portugal. Agora, ao passarmos para o século XX, é preciso analisar as novas funções estabelecidas para a gramática no Brasil.

\section{Gramatização do Português Brasileiro no século XX}

O panorama linguístico do século XIX desenhou os contornos para o processo da gramatização no século XX. Nesse período, já tínhamos a garantia de um Estado, consequentemente, houve um deslocamento político da língua que antes estava sob o domínio da colônia portuguesa, para se constituir enquanto elemento de afirmação de uma língua "genuinamente" elaborada em território brasileiro. Por conta disso é que se pode falar em "Língua Portuguesa no Brasil", justamente para assinalar que, após a consolidação do Estado, houve uma construção imaginária da unidade dessa língua e começou-se a pensar na propagação da Língua Portuguesa no Brasil, a partir de gramáticas elaboradas em território nacional.

Contudo, as primeiras gramáticas, ainda que desejassem manter um afastamento do Português europeu, visando justificar sua busca por uma necessidade de identidade linguística, ainda estavam permeadas pelas ideias científicas discutidas teoricamente nos outros países, que acabaram por afetar os termos gramaticais. Segundo Costa (2010, p. 44),

em decorrência das distintas filiações doutrinárias e de acordo com o ponto de vista pedagógico dos gramáticos, não tardou para que houvesse uma enorme profusão de nomes diversificados nos compêndios gramaticais (COSTA, 2010, p. 44).

A autora ainda afirma que, a partir de meados da década de 40, a nomenclatura gramatical começou a ser motivo de preocupação por conta do desconhecimento dos alunos, os quais tinham dúvida sobre qual terminologia teria legitimidade nos contextos relacionados a concursos oficiais. 
Isso contribuiu para fomentar o interesse pelos estudos relativos às terminologias dos manuais. É dentro desse contexto que a gramática de Eduardo Carlos Pereira (doravante ECP) ganha destaque. Segundo Orlandi $(2002,143)$, tal gramática foi uma "produção gramatical esfuziante", porque este manual foi adotado durante muito tempo como referência pedagógica e em decorrência disso alcançou o total de 102 edições.

Nesse sentido, a publicação da Gramática Expositiva assume uma fama resultante do trajeto que ECP formulou a partir do que já tinha sido direcionado por Júlio Ribeiro. Nesse sentido, Orlandi (2002) nos autoriza a dizer que ECP trilhou a vereda deixada por Júlio Ribeiro, promovendo por meio de sua gramática tanto a quebra de velhos modelos, os quais se referem à tradição gramatical portuguesa exemplificada pelo manual de Jerônimo Soares Barbosa, quanto o conflito sugerido pela associação à tradição que remonta à gramática filosófica e à gramática histórica.

Tendo isso em vista, verificamos que, na transição dos séculos XIX e XX, observa-se que, de um lado há o interesse dos brasileiros na constituição de uma língua "pátria", "nacional", "brasileira", visando à diferenciação do modelo de língua de Portugal e, por outro lado, há a uniformização do saber metalinguístico por meio da criação de compêndios gramaticais que pontuaram em seu interior a relação entre a gramática e a literatura.

Desse modo, a posição da gramática de ECP já se anuncia em seu título. Trata-se de uma gramática expositiva, cuja ênfase está na perspectiva pedagógica que, como tal, molda seu enquadramento o qual "corresponde ao modo normativo que se estabelece como relação com a língua na escola" (ORLANDI, 2002, p. 145). Nesse contexto, sob os termos de recurso didático, esse manual propõe ajustes nos prólogos das diferentes edições de forma que não se descuida dos objetivos pedagógicos anunciados. Ao empreender essa reflexão, Orlandi (2002) destaca a inserção de neologismos, além da ilustração do modelo de língua em torno da escolha de autores clássicos, em geral, portugueses, mas que, depois, por meio da literatura, houve a introdução de um autor brasileiro, a citar, Gonçalves Dias.

Com os estudos de Orlandi (2002), é possível afirmar que, mesmo que a gramática de ECP tenha sido adotada e conhecida no contexto escolar, sua circulação é interditada após ser outorgado o decreto que estabelece a Nomenclatura Gramatical Brasileira (NGB). Tal decreto, conforme Orlandi (2002, p. 160), "estabelece a homogeneidade de 
v. 7 (2)

$552-567$ ago/dez 2017

uma terminologia que desautoriza as variadas posições dos gramáticos que traziam para si a responsabilidade de um saber sobre a língua". No entanto, eis que surge, após a morte de Eduardo, o autor Evanildo Bechara, o qual não será responsável por adaptar o texto de Eduardo, mas por formular outra gramática.

Diferentemente da gramática de ECP, a gramática de Bechara oportuniza à Fonologia um domínio independente em paralelo com a Morfologia, a Sintaxe e a Semântica. Nessa direção, essa gramática se filia à gramática de ECP, porém entra em outro processo de autoria. Diante disso é que, conforme Orlandi (2002), a regulamentação da NGB provoca um deslocamento, pois a autoria do saber passa do gramático para a responsabilidade do linguista.

Desse modo, a gramática se torna o instrumento capaz de legislar sobre a língua. Após o estabelecimento da significação de uma língua nacional e de sua legitimação por meio do saber metalinguístico, a gramatização brasileira se efetiva, porém isso se configura muito antes de nos tornarmos independentes da nação portuguesa. No tocante a isso, Costa (2010, p. 27) ressalta que

o processo de gramatização brasileiro pode ser entendido como um início de um momento, que vem sendo processado desde antes de nossa independência, em que surgem novos sentidos, em que se configura uma nova subjetividade para $o$ povo brasileiro; não se trata mais simplesmente de um povo colonizado pela metrópole portuguesa, mas de cidadãos de uma nação independente e que, por isso, tem novas obrigações e deveres (COSTA, 2010, p. 27).

Assim, a nova subjetividade do povo brasileiro começa a ser construída a ponto de se poder falar em Português do Brasil, e a gramática tem o papel de propagar e instrumentalizar o saber metalinguístico. Diante disso é que a relação instaurada no século XX é entre brasileiros e brasileiros, e a gramática, por sua vez, concretiza-se como artefato científico. Ainda nesse tempo, o sistema da República vai contribuir para fomentar o surgimento de instituições escolares, bem como haverá uma preocupação consciente de um saber sobre a língua, que será materializado nos compêndios gramaticais.

\section{Rumos da gramatização do Português Brasileiro no século XXI}

Com o passar dos dois séculos, e a depender das necessidades do momento, a gramática assumiu variadas funções - elucidar, através 
de teorias linguísticas, fenômenos linguísticos, bem como explicar peculiaridades do Português Brasileiro, por exemplo. Por conseguinte, sua forma de lidar com diversos fatores também sofreu mudanças: as concepções de língua, assim como os corpora e a relação da gramática com seu público-alvo estão sendo revistos. Todavia, ela mantém uma relação de continuidade e descontinuidade com as gramáticas tradicionais dos séculos anteriores, pois, como afirma Leite (2014, p. 116, grifos da autora), "como objeto cultural, a gramática, mesmo mantendo a estrutura original, que constitui seu modelo, 'reflete e refrata' o conhecimento de seu tempo".

Desse modo, ao se deparar com as gramáticas atuais, não se pode deixar de pontuar a influência dos estudos linguísticos que vêm atuando em suas formações desde o início do século XX. Tais influências, conforme Leite (2014, p. 116, grifos da autora), ampliou o escopo das obras do século XXI, "para a linguagem, o discurso e o texto, em razão da evolução da ciência e da filosofia" e, além disso, a gramática, "modelo teórico, que serviu para gramatizar as línguas modernas ocidentais, permanece 'relativamente estável' e, ainda hoje, produtivo".

Aqui, analisamos duas gramáticas elaboradas no início da segunda década do século XXI, a citar, a Nova gramática do Português brasileiro, de Castilho (2010), e a Gramática pedagógica do Português brasileiro, de Bagno (2012). Ambas servem como exemplos de obras que ampliaram seu alcance e a própria noção de gramática, visto que as duas comportam a linguagem, o discurso e o texto. Para tal análise, recortamos apenas o Sumário e a Introdução, e adotamos os seguintes procedimentos: (i) como os linguistas-gramáticos definem suas gramáticas; (ii) verificar as concepções de língua; (iii) qual é o corpus utilizado em cada uma delas e o que os motivou a escolhê-lo; (iv) qual é o público-alvo de cada uma delas e (v) qual é a relação esperada entre esse público-alvo e o linguista-gramático.

Nova gramática do Português brasileiro, de Castilho (2010)

A Nova gramática do Português brasileiro (doravante NGPB), de Ataliba T. de Castilho (2010), é uma das obras desse gênero mais reconhecida desse século, pois, juntamente a outros autores de gramática, como Maria Helena de Moura Neves, Marcos Bagno, Evanildo Bechara, Mário Perini etc., visa a oficializar as características do PB e a contribuir para que lidemos melhor com a nossa língua, assegurando-a enquanto legítima. 
v. $7(2)$

$552-567$ ago/dez 2017

Logo no início de sua introdução, Castilho (2010, p. 31) afirma que "faltava clarificar a gramática do Português brasileiro, para dar status científico à sua percepção", afinal, foi através de estudos acerca da nossa língua em diversas universidades que o autor se fundamentou para a produção da obra.

A partir disso, ele classifica sua gramática não como uma "gramática escolar usual" nem como "uma gramática ateórica", pois ela "não é uma gramática-lista cheia de classificações em que não se vê a língua" (CASTILHO, 2010, p. 31). Quanto às classificações, é possível notar, desde o sumário, que Castilho traz uma nomenclatura que diverge parcialmente das GN, tal como a de Bagno (2012), como será visto a seguir, que também é fundamentada em teorias linguísticas.

Sua concepção de língua também é muito diferente da defendida nos séculos anteriores, sempre embasadas em escritores canônicos e no que era concebido como "belas letras", tanto que, para ele, "o objetivo das boas gramáticas é desvelar o conhecimento linguístico armazenado na mente dos falantes, desde o cidadão analfabeto até o escritor laureado" (CASTILHO, 2010, p. 32, grifos nossos).

Os corpora que constituem a gramática de Castilho são um exemplo disso, visto que, como afirma Leite (2014, p. 127, grifos nossos), a escolha por determinado corpo está relacionada à filiação teórica de cada autor, o que explica "Castilho e Bagno, que operam com teorias diversas, funcionalistas, gerativistas/cognitivistas, pragmáticodiscursivas em geral, terem usado exemplos de uso na fala e na escrita, mas também muitos forjados por eles mesmos".

Além de servir como corpora reais, os falantes são colocados em uma posição que ultrapassa a de leitor, já que Castilho (2010, p. 32) propõe "ao leitor que se envolva nas pesquisas, transformando-se no linguistagramático dele mesmo". Dessa forma, o autor aceita que a sua língua pertence a esses falantes/leitores também, de modo que eles não devem ser apenas receptores de informações acerca de sua própria língua.

No tocante a isso, o linguista critica o "estilo revelação" adotado por algumas gramáticas, no qual "o gramático se transforma numa espécie de Moisés que desce dos altos montes e revela aos povos estupefatos... o que está certo e o que está errado em sua linguagem!" (CASTILHO, 2010, p. 32). Aqui, percebese mais uma vez um posicionamento divergente ao aderido pelos autores de gramáticas normativas, que se assumem como o "Moisés" da língua, afinal, Castilho deixa de trazer "revelações" e passa a encaminhar as discussões para momentos de problematizações e diálogos em torno dos usos do PB. 
Seu público-alvo, composto pelos "professores do ensino médio, os alunos do curso superior, os professores universitários [...], e as pessoas que se sintam atraídas pelo mistério das línguas naturais" (CASTILHO, 2010, p. 33), mantém um diálogo com o autor durante toda a leitura.

Um exemplo desse diálogo está no capítulo 15, intitulado "Algumas generalizações sobre a gramática do português brasileiro. A reflexão gramatical", no qual o autor orienta o leitor de modo que ele possa fazer suas próprias análises - ele mostra ao leitor possíveis caminhos a seguir, como a escolha por um problema e por uma perspectiva teórica, a formulação de hipóteses, a maneira como se deve analisar e obter os resultados etc.

De todo modo, mantendo sua relação de continuidade e descontinuidade com as gramáticas normativas, Castilho (2010, p. 33) afirma que pretende

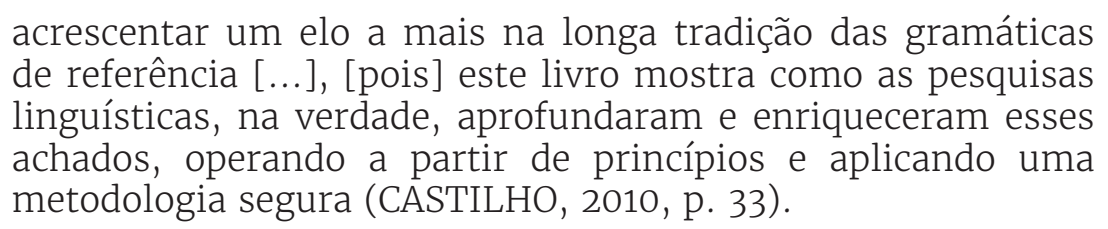

acrescentar um elo a mais na longa tradição das gramáticas de referência [...], [pois] este livro mostra como as pesquisas linguísticas, na verdade, aprofundaram e enriqueceram esses achados, operando a partir de princípios e aplicando uma metodologia segura (CASTILHO, 2010, p. 33).

Com tal postura, diferentemente da esperada na relação entre gramática normativa versus gramáticas do Português brasileiro contemporâneo, Castilho reconhece a importância daquelas para a elaboração destas que, por meio dos estudos da Linguística moderna, aprimoraram os pressupostos tradicionais.

Gramática pedagógica do Português brasileiro, de Bagno (2012)

A Gramática pedagógica do Português brasileiro (doravante GPPB), de Marcos Bagno, mesmo recebendo o nome de gramática não atende a todos os requisitos exigidos por quem espera que ela seja mais um compêndio cheio de classificações, nomenclaturas e delimitações em torno da língua.

Percebemos isso desde o seu Sumário, no qual todos os títulos trazem relações entre a língua e sua formação, assim como sua história e a história de seu povo - este é dividido em cinco livros, com os seguintes nomes: I - Epistemologia do português brasileiro; II - História do português brasileiro; III - Multimídia do português brasileiro; IV - Lexicogramática do português brasileiro e V - Didática do português brasileiro. 
V. 7 (2)

$552-567$ ago/dez 2017

Todavia, para verificarmos quais são os propósitos do autor, decidimos analisar, também, a apresentação da gramática, intitulada "Aviso aos navegantes". Nela, como o próprio nome diz, Bagno decide caracterizar a sua obra, de modo que aqueles que a procurem como fonte de informações não se decepcionem ao não encontrar determinadas respostas.

Primeiramente, o linguista a classifica como uma gramática, "na medida em que pretende examinar e descrever o funcionamento de uma língua específica, o português brasileiro contemporâneo" (BAGNO, 2012, p. 13, grifos do autor). Aqui, já se percebe uma delimitação muito grande em seu objeto de estudo, afinal, como o autor afirma, "é preciso reconhecer o PB como uma língua que dispõe de uma gramática muito distinta não só do português europeu como também das línguas românicas em geral" (BAGNO, 2014, p. 101-102).

Legitimar a língua falada no Brasil "é 'o processo de dar 'idoneidade' ou 'dignidade' a uma ordem de natureza política, para que seja reconhecida e aceita' (HABERMAS, 1976)" (GNERRE, 1991, p. 08), pois, na relação entre língua e poder, negar o valor de uma determinada língua gera "perversos efeitos simbólicos", como "baixa autoestima cultural, sentimento de incompetência linguística, mitificação de uma 'língua certa' tornada inacessível ao falante comum" etc. (BAGNO, 2014, p. 102).

A segunda característica dada pelo autor à GPPB é que ela é propositiva,

porque não se limita a descrever ou a expor o português brasileiro, mas propõe efetivamente a plena aceitação de novas regras gramaticais que já pertencem à nossa língua há muito tempo e, por isso, devem fazer parte do ensino sistemático da língua" (BAGNO, 2012, p. 14, grifos do autor).

Esse segundo aspecto abrange questões relacionadas ao ensino, estando diretamente atrelado à terceira característica, qual seja, ela é pedagógica, "porque foi pensada para colaborar com a formação docente que, no Brasil, é reconhecidamente falha e precária" (BAGNO, 2012, p. 14, grifos do autor).

A quarta característica é que essa gramática "é um projeto epistemológico porque traz explícita uma teoria do conhecimento, destinada a fundamentar os posicionamentos francamente assumidos ao longo de todo o texto" (BAGNO, 2012, p. 14, grifos do autor). A quinta característica é que ela é político-ideológica, pois, segundo seu 
próprio autor, "o mito da ciência 'neutra' não tem mais lugar na era em que vivemos. Assim, essa obra milita a favor do reconhecimento do português brasileiro como uma língua plena, autônoma" (BAGNO, 2012, p. 14). Logo, o autor assume a posição de luta contra o preconceito existente diante de características do PB, muitas vezes preteridas diante do Português de Portugal.

Ademais, também luta pela legitimação, como já citado, dessas características, além de reconhecer, devido à sua postura política declarada, que

[...] a língua padrão é um sistema comunicativo ao alcance de uma parte reduzida dos integrantes de uma comunidade; é um sistema associado a um patrimônio cultural apresentado como um 'corpus' definido de valores, fixados na tradição escrita (GNERRE, 1991, p. 06).

Portanto, o preconceito sofrido pelos falantes das variações estigmatizadas, além de ser um preconceito linguístico, também é social - já que ambos estão intrinsecamente associados, afinal, como afirma Gnerre (1991, p. 05), "uma variedade linguística 'vale' o que 'valem' na sociedade os seus falantes, isto é, vale como reflexo do poder e da autoridade que eles têm nas relações econômicas e sociais".

A sexta característica é o seu caráter teórico, visto que "discute, refuta ou abraça propostas anteriores de descrição da língua e em que propõe novas análises, definições e conceitos" (BAGNO, 2012, p. 14). Um exemplo disso é sua alteração na classificação clássica no que tange às formas nominais dos verbos, "uma classe que [Bagno] denominou 'verbinominais', o que lembra a classificação tradicional que considerava o particípio uma classe, por suas propriedades também nominais" (LEITE, 2014, p. 132).

Por fim, a sétima e última característica destinada à gramática de Bagno é que ela é histórica, "porque rejeita a tradicional separação entre diacronia e sincronia, e assume o fenômeno linguístico como eminentemente pancrônico, variável e mutante" (BAGNO, 2012, p. 14, grifos do autor).

A postura do linguista apresenta descontinuidade com a tradição, observada inclusive através de seu corpus, pois, diferentemente da GN, que exemplifica suas regras através de excertos de gêneros literários, Bagno (2012, p. 27, grifos do autor) trata de "uma norma que já existe, 'tácita ou recalcada', e que tem de ser legitimada para que o Brasil exorcize de vez o fantasma colonial que ainda assombra nossas concepções de língua e de língua e ensino". 
v. $7(2)$ $552-567$ ago/dez 2017

Quanto ao seu público-alvo, Bagno (2012, p. 20, grifos do autor) afirma que sua obra

tem, primordialmente, no seu horizonte de leitores potenciais, as professoras e os professores em formação ou já formados que exercem o magistério no ensino fundamental e/ou médio e na educação de jovens e adultos, ou que se preparam para essa tarefa (BAGNO, 2012, p. 20).

Para Bagno (2014, p. 94, grifos do autor), portanto, seu papel social enquanto linguista é de "agente capaz de transformar, graças ao conhecimento acumulado sobre a língua, as relações sociais por meio da linguagem".

A gramática, enquanto um gênero relativamente estável, mantém uma relação de continuidade e descontinuidade entre a tradição e a linguística, e a Gramática pedagógica do português brasileiro é um exemplo disso - sendo, entretanto, uma das maiores revolucionárias no seu propósito até hoje, afinal, desde a sua estrutura (que está longe de ser uma lista cheia de nomenclaturas decoráveis e limitadoras) até as suas intenções (pois não visa a categorizar e pormenorizar todos os fenômenos linguísticos), ela é a que mais diverge de todas as outras.

Gramáticas no século XXI: prospecções iniciais

As discussões apresentadas nos tópicos anteriores sobre os aspectos relevantes dos exemplares de GBCP (Gramáticas Brasileiras Contemporâneas do Português) aqui analisados nos oferecem condições de explicitar sobre uma possível definição do que são esses manuais: são compêndios recentes que têm sido reconhecidos principalmente no meio acadêmico.

Recorremos, então, às teorizações apresentadas por Vieira (2016, p. 28) para afirmar que os linguistas, ao mesclarem a abordagem tradicional às teorias linguísticas em seus compêndios, acabam por não desnaturalizar a tradição. Segundo o autor, "o linguista ainda não conseguiu se desvencilhar por completo do arcabouço conceitual e categorial que os antigos gramáticos nos deixaram de legado". Todavia, as rupturas se revelam, porque tais gramáticas já propõem se afastar daquelas gramáticas normativas que apresentavam listas de classificações.

Outra ruptura paradigmática que as distancia das normativas é a fundamentação em teorias linguísticas. A GC, por sua vez, admite uma teoria multissistêmica com forte conteúdo funcionalista- 
cognitivista, já a base teórica da GB ressalta que o enfoque deve ser, portanto, essencialmente semântico-pragmático-discursivo. Desse modo, pode-se notar um movimento de ruptura, porque, enquanto a gramática normativa se estabelece como ateórica, essas gramáticas já se fundamentam teoricamente. Todavia, isso serve apenas para escamotear o apagamento de continuidade com a tradição, pois, de acordo com Vieira (2016), tais gramáticas não extinguem todas as linhas que dão continuidade ao viés tradicional, mas já entendem que este padrão não acomoda o novo fazer gramatical proposto pelo século XXI.

Em consonância a isso, Vieira (2016, p. 54) afirma que, nesse movimento de continuidade-descontinuidade, "as GBCP por um lado se deslocam da epistemologia tradicional e, por outro lado, guardam semelhanças com a tradição gramatical luso-brasileira". Assim, o autor ressalta que, entre as gramáticas do início do século XXI, os maiores movimentos de ruptura são despontados na GB. Isto porque a GB absorve parte das pesquisas linguísticas de teor funcionalista, cuja singularidade está em trabalhar com o corpus linguístico extraído do projeto NURC. Apesar disso, os excertos literários de autores contemporâneos continuam sendo utilizados como exemplos.

Desse modo, entendemos que, longe de ser apenas uma revolução científica, a revolução do fazer gramatical é de cunho político. Nesse sentido, Vieira (2016, p. 39) reconhece que o esforço empreendido pelas produções gramaticais do século XXI seria um pontapé inicial no que se refere a promover um deslocamento de um pensamento que está "interditado por séculos históricos de dominação teórico-ideológica do pensamento gramatical circunscrito ao PTG". Aqui, destacamos a preocupação de Bagno, enquanto autor, em reconhecer o viés ideológico já nas primeiras páginas do seu manual, conforme foi apontado no tópico da seção anterior.

Com isso, intuímos os sinais de que ainda somos testemunhas de um deslocamento que pressupõe os primeiros passos de descontinuidade com as tendências marcadas pela tradição. Com efeito, Vieira (2016, p. 45) levanta a hipótese de que "o espaço das gramáticas tradicionais do português foi pouco abalado com essas novas publicações, as quais se respondem às urgências da virada linguística, não atendem às demandas ordinárias de um livro de gramática". E, é pertinente destacar, ainda segundo Vieira (2016), que não há gramáticas tradicionais sendo lançadas no mercado atualmente (pelo menos não em sua primeira edição), enquanto que gramáticas elaboradas por linguistas estão a todo vapor. 
v. 7 (2) 552-567 ago/dez 2017

Nessa direção, o autor sugere que, enquanto prospecção futura, devem-se conceber outras motivações político-ideológicas, as quais sejam capazes de atravessar o atual panorama teórico-metodológico. Portanto, se faz necessário que se atente para que, além de prometer um encaminhamento metodológico, mantenha-se a coerência deste no interior dos manuais durante as abordagens.

\section{Considerações finais}

O percurso teórico-analítico exposto até aqui pôde nos oferecer condições de mostrar como o embate configurado pelas gramáticas analisadas revela o lugar destinado a cada concepção de manual no início do século XXI. Dessa maneira, não se pode falar em abolir o modelo de gramática enquanto instrumento apenas normativo, visto que as gramáticas operam dentro de um movimento de continuidadedescontinuidade com o padrão tradicional gramatical. Todavia, as análises elaboradas com essa pesquisa indicam que as gramáticas recentes promovem movimentos de ruptura ao que já está posto pelos manuais anteriores.

Diante disso, inferimos que o novo paradigma que se estabelece no século XXI não pode desconsiderar que, conforme Vieira (2016, p. 30-31), "as políticas educacionais e o próprio contexto histórico do Brasil se configuraram de modo que a tradição gramatical brasileira se desenvolvesse com mais continuidades e assentamentos do que com rupturas significativas". Nesse sentido, concordamos com o autor quando ele diz que é preciso que a geração de novos pesquisadores esteja disposta a abraçar o novo paradigma no sentido de explorá-lo a fim de retratar os contornos dos estudos gramaticais no presente século.

Assim, o olhar de futuras prospecções deve ter como base a urgência de outras motivações político-ideológicas, que atravessem o atual panorama teórico-metodológico apresentado e sugerido pelos "novos manuais". Portanto, convém se instaurar uma revolução política que seja suficiente para aprofundar as rupturas já iniciadas pelos manuais que se apresentam bem como para que se possa desconfiar desse "novo" que nos é proposto através desses compêndios. 


\section{Referências}

AUROUX, S. A revolução tecnológica da gramatização. Campinas/SP: UNICAMP, 1992.

CASTILHO, A. T. de. Nova gramática do português brasileiro. São Paulo: Contexto, 2010.

Sobre a Nova gramática do português brasileiro. In: NEVES, $M$. H. de M., CASSEB-GALVÃO, V. C. (orgs.). Gramáticas contemporâneas do português: com a palavra, os autores. São Paulo: Parábola Editorial, 2014.

COSTA, T. de A. da. Gramáticas pós NGB: do discurso oficial a outros discursos (im)possíveis. 2010. 133f. Dissertação (Mestrado). Universidade do Estado do Rio de Janeiro, Rio de Janeiro, 2010.

BAGNO, M. Gramática pedagógica do português brasileiro. São Paulo: Parábola editorial, 2012.

Uma gramática propositiva. In: NEVES, M. H. de M., CASSEBGALVÃO, V. C. Gramáticas contemporâneas do português: com a palavra, os autores. São Paulo: Parábola Editorial, 2014.

GNERRE, M. Linguagem, poder e discriminação. In: escrita e poder. 3. ed. São Paulo, 1991.

Linguagem,

LEITE, M. Q., Tradição, invenção e inovação em gramáticas da língua portuguesa - séculos XX e XXI. In: NEVES, M. H. de M., CASSEB-GALVÃO, V. C. Gramáticas contemporâneas do português: com a palavra, os autores. São Paulo: Parábola Editorial, 2014.

ORLANDI, E. P. Conhecimento linguístico, Filologia e Gramática. In:

Língua e conhecimento linguístico: para uma história das ideias no Brasil. Cortez: São Paulo, 2002.

PÊCHEUX, M. Semântica e discurso: uma crítica à afirmação do óbvio. 2. ed., Campinas: Editora da Unicamp, 1997 [1975].

VIEIRA, F. E. Gramatização brasileira contemporânea do português: novos paradigmas? In: FARACO, C. A., VIEIRA, F. E. Gramáticas brasileiras: com a palavra, os leitores. São Paulo: Parábola Editorial, 2016.

Recebido em: 15 de fev. de 2017.

Aceito em: 30 de jul. de 2017. 